\title{
Exploring Causes and Countermeasures of the Employment Difficulties for College Graduates in the New Era
}

\author{
Xuemei Ni \\ Department of Employment and Entrepreneurship, Chifeng University, Chifeng, Inner Mongolia, \\ China \\ 120402805@qq.com
}

\section{Keywords: Employment difficulties; Causes; Countermeasures}

\begin{abstract}
This paper focuses on the increasingly prominent problem of employment difficulties that college graduates confront. Through analyzing the major causes of the employment difficulties and investigating the impact that the society, universities, families and individuals have on college graduates' employment, the paper proposes some solutions to the problem from several aspects: the government measures, talent-cultivating adjustment of universities, the changes of employment concepts as well as mindset adjustment from the perspective of families and individuals, and the ideological innovations of employers, etc.

In the new era when the national economy develops rapidly, the national economic restructuring and the enrollment increase in institutions of higher learning makes the employment difficulties for college students even more prominent, which has become a serious social problem. There are a lot of reasons contributing to this issue, such as social elements, tertiary education, family influences and individual factors. It is extremely urgent to solve this problem in order to efficiently make use of the talents and promote further development of the national economy.
\end{abstract}

\section{Cause Analysis of the Employment Difficulties in the New Era}

Economic restructuring has increased college students' employment pressure. In the new normal situations of economic development, our country has been constantly adjusting the economic structure in order to defuse the excessive production capacity and get rid of the backward productivity, causing a proportion of enterprise employees to lose their jobs; the unemployed people pour in to the labor market and become competitors of college graduates [1]. At the same time, as the pressure of the economic downturn is becoming greater, some enterprises confront difficulties in production and management; as a result, their recruitment capacity is insufficient and there are less and less job vacancies.

In addition, institutions of higher learning have been implementing the national policy of enrollment increase, so there are more and more college graduates pouring in to the job market every year. According to the statistics, there were more than 1.4 million college graduates in the year 2002, and the number soared up to 7.95 million in 2017. The sharp increase of college graduates has far exceeded the growth rate of the economy, intensifying the conflict between the total supply and demand in the job market.

Furthermore, the enrollment increase also caused the imbalance between the social needs and universities' specialty structure and talent structure. As a supporting power of sustainable economic development, the development of the specialty structure in institutions of higher learning should adapt to the changes in the economic structure and provide all kinds of qualified and equivalent labor force and professionals for scientific and technological progress and sustainable economic development. But since the implementation of the enrollment increase, many colleges and universities didn't have scientific demand forecasting and planning for cultivating talents, and the major setup was inconsistent with social needs. Consequently, college graduates' specialized knowledge structure was in disharmony with the social demand. What's worse, colleges and universities increased the enrollment in their regular majors, especially in the hot majors, and set up many new majors in order to enroll more students. When these students graduated, they found that 
the graduates far outnumbered the social demand. Hence a fairly great number of students became unemployed immediately after they graduated.

The inconsistency between talent cultivating in institutions of higher learning and the social demand. Currently, the major problems of the talent cultivating mechanism of the institutions of higher learning in China lies in that it is inconsistent with the social demand, and the talent training standard doesn't conform to the social needs [2]. For example, it is quite common that college graduates' qualities and capabilities can't meet the requirements of transnational corporations. At present, the major setup, the enrollment scale and the talent cultivating of institutions of higher learning mainly depends on the planning and regulations of the educational administrative departments, instead of the social development and social needs, bringing about the unreasonable major setup. There are too many students majoring in some disciplines with relatively lower employment chances, and the lack of practical abilities worsens the odds of employment.

The main aim of higher education is to serve the development of the society and the economy, while the realization of the aim relys mainly on the employment of college graduates. However, the current professional curriculum design in institutions of higher learning still focuses on students' learning, rather than aim to satisfy the social needs, causing the discrepancy between universities' talent cultivating and the social demand. While searching and applying for jobs, many college graduates sadly find that what they have learned during the past four years is quite different from the jobs that they are applying for, which has greatly reduced their employment competitiveness and becomes a barrier on their way to finding an appropriate job.

The interference of families has huge impact on college graduates' job options. Today, most college graduates are post-95s, and the majority of them are the only child in their family, and families play an increasingly great role in their job options. Parents and children are different in their ways of thinking, and they differ greatly in their world outlook and values. But some parents intend to impose their opinions and ideas on their children when they are looking for jobs, regardless of children's real needs, interests and strengths, which may cause a dilemma for some college graduates [3]. In addition, many parents cradle their children too much and have spoiled them. College students have weak will power, lack independence and sense of responsibility, rely on their parents too much, and have no ideas of their own while searching for jobs. Furthermore, the economic status of students' families also has important influence on their job hunting. Students from relatively poor families may have higher expectations for salary and welfare, but they are also more prone to be anxious and suffer greater pressure, which is unfavorable to employment.

In a word, family atmosphere, economic status, educational background of family members, as well as the ideas and suggestions of family members may all greatly influence college graduates' employment choices and interfere their effective decision.

College graduates' insufficient knowledge of themselves. College graduates don't have correct knowledge of themselves, which is also an important reason for their employment difficulties. Currently, college graduates of the current year generally don't have correct knowledge of their own abilities and levels, and they tend to have a high opinion of themselves; others don't seriously analyze their personalities, self-realization, interests and strengths, and they blindly follow the trend of registering for the civil servant examination in order to become staffs of government affiliated institutions [4]; still others limit a lot of conditions for their potential jobs, such as location of the employers, whether the jobs match their majors, the type of the enterprises, and the work environment, etc. These limiting conditions further contribute to the employment difficulties of college graduates.

\section{Research on the Countermeasures against the Employment Difficulties}

Strengthening the Government's Policy and Institutional Support to Facilitate College Graduates' Employment. The government is facing the severe challenge of employment pressure from the society as a whole. Only when the government gives policy guidance to employment from the macro level can the market regulate from the micro level [5]. For example, the government can create more job opportunities and better work environment by analyzing the social demand while 
making educational systems and policies, talent cultivation standards, major setup standards in institutions of higher learning, employment regulations of employers and employment policies. In so doing, it will greatly relieve the employment difficulties of college graduates.

Combining Talent Cultivation in Institutions of Higher Learning with the Employment Market. One of the reasons that the society has insufficient demand for college graduates is that the structure of talents cultivated by institutions of higher education doesn't conform to the structure of the social needs. Therefore, to solve the employment difficulties, the structure of talent cultivation in institutions of higher education must be changed and modified so as to better satisfy the structural needs of the job market [6]. Structural modification may include adjustment of major setup and the proportion of various kinds of education. Besides, the quality of higher education also needs to be improved, since lower-quality education will inevitably affect students' employment competitiveness in the job market. As a consequence, talent cultivation in institutions of higher learning should be employment oriented, aim to improve students' practical abilities, cultivate their potentials, train their innovation capability, and enhance their social adaptation ability and enterprising spirit.

Institutions of higher learning should start from their own problems, investigate and analyze the social demand in order to learn more about the talent demand in the new era, modify their talent cultivation plans, so that they can remove the discrepancy between talent cultivation and social demand. In addition, institutions of higher learning can strengthen their cooperation with enterprises, integrate the campus culture with the corporate culture, encourage enterprises to provide more opportunities for college students for their internship, help students gain more practice and experience, and enhance their employability and employment competitiveness [7]. Institutions of higher learning must also pay attention to students' feedback on their internship and employment, based on which the teaching contents can be renewed. Major setup and orientations must be constantly adjusted with the continuous changes of job market and development of knowledge. In this way, the employment difficulties will be further relieved.

Transforming the Employment Concepts of Families to Guide Students to Get Employed Positively. The employment concepts of families play a significant role in their job hunting. "Parents of college graduates should transform their concepts actively, form a favorable way of thinking, collect employment information in the society, gain a comprehensive knowledge of the employment situations and policies, and get rid of the bond of traditional concepts. They should give scientific guidance to their children by organically combining their subjective desires with the regional and national economic development, political situations, the employment policy orientations, prospect of industry development, career nature, job requirements, and so on [8]'. Parents should care more about their children, give them more guidance and respect them better; parents should also understand children's interests and hobbies, their occupational values, and reduce interference in their choices; parents should give children free room to make choices by themselves instead of imposing their opinions on their children, provide necessary guidance and suggestions, and relieve their stress and depression when they are trapped in employment dilemma.

Strengthening Employment Competitiveness in the Job Market through Developing Comprehensive Abilities. College students should develop a clear understanding of their future potential career at the beginning of their college life. If so, they can formulate a scientific career plan which may guide their years of college life. During the four years, they can constantly modify their career plans according to the development of their abilities and qualities as well as the improvement of their cognition [9]. Besides, according to their career plans, they can consciously train their comprehensive abilities correspondingly from aspects of knowledge levels, career capabilities, team spirit, job hunting and interview skills, etc. Thus they will improve their employment competitiveness and make full preparations for their job hunting, which will definitely increase their odds of finding an ideal job smoothly.

Moreover, college students should be encouraged to start their own business voluntarily, which will not only get themselves employed but also create job opportunities for others. This is of crucial realistic significance to solve the employment difficulties. Therefore, the government should 
formulate a series of preferential policies and create a favorable social environment to encourage students to get self-employed [10].

\section{Conclusion}

In the new era when the situations of socialist marketing economy are constantly changing, college graduates are facing unprecedented severe employment situations and huge employment pressure, and it is increasingly more difficult to find a good job these days. But it is firmly believed that the employment difficulties will be effectively solved with the joint efforts of the society, colleges and universities, families and students themselves.

\section{References}

[1] Y.B.Lin: Analysis of the Reasons for the Difficult Employment of College Students and Discussion on the Guidance and Countermeasures: Modern Business Trade Industry, Vol. 22(2010) No.16, p. 166-168.(In Chinese)

[2] Lent R.W. et al: Toward a Unifying Social Cognitive Theory of Career and Academic Interest, Choice and Performance. Journal of Vocational Behavior, Vol. 45(1994) No. 7, p. 79-122.

[3] P.He: New Thinking on the Problem of College Students' Employment: Journal of Shandong Youth University of Political Science, Vol. 27(2011) No.1, p. 72-76.(In Chinese)

[4] J.Wang and X.Shhi: Investigation on the Current Situation of College Students' Professional Consciousness and Training Countermeasures: Vocational Education Research, Vol. 11(2009) No. 9, p. 69-71.(In Chinese)

[5] L.L.Zhang: Study of Government Responsibility in the Employment of College Students, Henan Social Sciences, Vol. 17(2009) No. 3, p. 96-98.(In Chinese)

[6] X.S.Liang and Y.P.Deng: Research on the Training of "Professional Adaptability" Talents in the School Enterprise Alliance: Research in Education Development, Vol. 33(2013) No.9, p. 59-63+73.(In Chinese)

[7] J.B.Huang: Analysis of the Employment Ability Oriented College Education System Reform: Heilongjiang Researches on Higher Education, Vol. 30(2012) No. 6, p. 130-132.(In Chinese)

[8] Y.H.Zhou: Analysis on the Causes of College Students' Difficulties in Employment and the Countermeasures: Journal of Changchun University of Science and Technology(High Education Edition), Vol. 5 (2010) No.1, p. 88-89.(In Chinese)

[9] C.Ge, C.J.Feng and N.Li: Analysis of the Reasons for Employment Difficulties and the Countermeasures: Journal of Agricultural University of Hebei(Agricure \& Forestry Education), Vol. 12 (2010) No. 3, p. 359-361+365.(In Chinese)

[10]D.Zhao: Analysis of the Social Policy of Getting out of the Employment Dilemma of College Students: Journal of Northeast Agricultural University(Social Science Edition), Vol. 7(2009) No.1, p. 74-75.(In Chinese) 